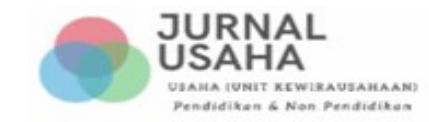

Vol 1, No. 1 (2020), June 2020

E-ISSN: 2746-2471

\title{
MODEL PLATFORM e-COMMERCE DALAM MENDUKUNG KESUKSESAN UMKM DI INDONESIA
}

\author{
Tedy Ardiansyah \\ Universitas Indraprasta PGRI \\ tedyardiansyah@unindra.ac.id
}

\begin{abstract}
Abstrak
Penelitian mengenai kesuksesan UMKM (Usaha Mikro Kecil dan Menengah) di Indonesia masih sangat jarang terutama yang menyangkut mengenai e-commerce terkhusus pada platform atau aplikasi, bukan itu saja, namun dukungan dan model bisnis dari UMKM menjadi bagian pokok dari kesuksesan UMKM. Tujuan penelitian ini adalah untuk mengetahui Model platform e-commerce pemain digital bisnis dalam mendukung kesuksesan UMKM di Indonesia. Metode yang digunakan dalam penelitian ini adalah penelitian kualitatif dimana pendekatan yang dilakukan melalui studi literatur yaitu penelitian yang mengkaji secara kritis pengetahuan, gagasan atau temuan serta memberikan kontribusi teoritis dan metodologis terhadap objek kajian. Hasil penelitian ini menunjukan bentuk dari model yang tepat untuk kesuksesan UMKM di Indonesia melalui platform e-commerce dari berbagai pemain digital bisnis.
\end{abstract}

Kata kunci: platform, e-commerce, kesuksesan, UMKM, Indonesia

\section{A. LATAR BELAKANG}

Pada tahun 2020 mendatang produk Usaha Mikro Kecil Menengah ( UMKM) mampu bersaing dengan produk luar negeri. Namun saat ini Marketplace $60 \%$ produk dari luar sisanya local sebanyak 40\%. Target yang diharapkan pada tahun 2020 ini adalah sebesar $80 \%$. Potensi berbagai produk UMKM untuk dikembangkan masih besar, karena UMKM di Indonesia sendiri jumlahnya mencapai 59 juta Sementara itu, salah satu e-commerce dalam negeri yang tengah fokus membangun produkproduk dalam negeri yaitu Blibli.com menargetkan pada 2020 mendatang produk UMKM lokal bisa mencapai 30 hingga 40 persen. "Dari 25.000 partner, UKM-nya antara 500 sampai 1.000.(Pramdia Arhando Julianto, 2020). Tentunya hal ini masih menjadi PR bagi pemerintah dalam menangani UMKM di usaha dagang di dunia maya. Namun beberapa upaya juga telah dilakukan oleh pemerintah. Kementerian Informatika dan Informasi (Kominfo) gencar mendorong pelaku usaha mikro kecil dan menengah (UMKM) untuk segera mengenal marketplace sebagai media usaha. Adanya ekosistem baru itu diharapkan akan memudahkan pemangku kepentingan melakukan pembinaan."Berdagang di marketplace ini kan butuh trik-trik tertentu. Mereka yang baru bergabung (di marketplace) butuh pembinaan lebih jauh agar mereka segera go digital. Harapan dari marketplace maupun dari dinas-dinas 


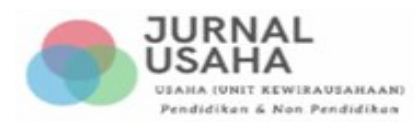

Vol 1, No. 1 (2020), June 2020

E-ISSN: 2746-2471

terkait segera melakukan pendampingan dan pembinaan agar pelaku UMKM ini merasakan manfaat hadirnya platform digital yang lebih aman dan nyaman untuk berdagang. Bergabungnya para pelaku UMKM di pasar-pasar ke marketplace akan membuka peluang baru berkembangnya pasar tradisional ke pasar digital. Tidak lagi hanya mengandalkan caracara konvesional, pedagang juga dapat aktif berdagang di kanal-kanal e-commerce(Widianto, 2019). Para Jagoan digital business yang ada di Indonesia telah berhasil membangun platform bisnis yang menciptakan saling ketergantungan dan simbiosis muatualisme antara perusahaan UMKM. Namun apakah platform ini akan menjadi wahana ampuh bagi jutaan UMKM untuk melipat gandakan bisnis dan mana platform yang dapat membangun ekosistem yang merangkul dan memberdayakan UMKM. Beranjak dari latar belakang tersebut peneliti akan menyajikan telaah literature mengenai model platform e-commerce pemain digital bisnis dalam mendukung kesuksesan UMKM di Indonesia.

\section{B. KAJIAN PUSTAKA}

Usaha Kecil, dan Menengah (UKM) mempunyai peran penting dan strategis bagi pertumbuhan ekonomi negara, baik negara berkembang maupun negara maju. Kemampuan UKM perlu diberdayakan dan dikembangkan secara terus menerus dengan berusaha mereduksi kendala yang dialami UKM, sehingga mampu memberikan kontribusi lebih maksimal terhadap peningkatan kesejahteraan masyarakat (Sutaryo, 2004). UKM menjadi tumpuan untuk menghasilkan nilai tambah, penciptaan lapangan kerja, dan sumber devisa. Tidaklah mengherankan jika UKM menjadi sektor yang eksotis sehingga menjadi bagian penting dari persaingan perdagangan internasional. Negara yang berhasil menjadi negara maju juga memiliki keberhasilan dalam memajukan sektor usaha kecil dan menengah. Sebagaimana diatur dalam Undang-Undang Nomor 20 Tahun 2008 tentang Usaha Kecil dan Menengah maka Usaha Kecil didefinisikan sebagai usaha ekonomi produktif yang berdiri sendiri, yang dilakukan oleh orang perorangan atau badan usaha yang bukan merupakan anak perusahaan atau bukan cabang perusahaan yang dimiliki, dikuasai, atau menjadi bagian baik langsung maupun tidak langsung dari usaha menengah atau usaha besar yang memenuhi kriteria Usaha Kecil. Sedangkan Usaha Menengah didefinisikan sebagai usaha ekonomi produktif yang berdiri sendiri, yang dilakukan oleh orang perseorangan atau badan usaha yang bukan merupakan anak perusahaan atau cabang perusahaan yang dimiliki, dikuasai, atau menjadi bagian baik langsung maupun tidak langsung dengan usaha kecil atau usaha besar dengan jumlah kekayaan bersih atau hasil penjualan tahunan sesuai dengan kriteria yang diatur dalam Undang-Undang.

Dunia yang semakin canggih dan teknologi semakin berkembang. Perkembangan tersebut secara langsung maupun tidak langsung mempengaruhi sistem perdagangan, transaksi dan peredaran uang selama ini. Sebelumnya, transaksi secara tradisional dilakukan dari tangan ke tangan secara langsung, antara pembeli dan penjual bertatap muka, melakukan persetujuan dan akhirnya terjadi kesepakatan. Namun kini, dengan adanya kecanggihan teknologi komputer, semua keterbatasan sarana, jarak, dan waktu transaksi dapat teratasi 


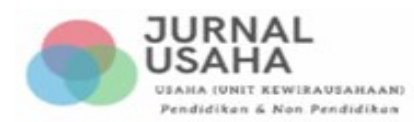

Vol 1, No. 1 (2020), June 2020

E-ISSN: 2746-2471

dengan mudah.Di jaman era globalisasi UKM mendapat banyak persaingan dari perusahaanperusahaan besar, untuk tetap bisa berkompetitif UKM seharusnya menggunakan Teknologi Informasi (TI) dalam tingkatan yang sesuai dengan ukuran perusahaan. Tanpa hal itu diyakini bahwa UKM akan tetap lemah dibandingkan dengan perusahaan besar dalam hal pemasaran, perdagangan, keterampilan manajerial, dan sebagainya.

TeknologiInformasi (TI) sebenarnya hadir sebagai penyelamat bagi UKM karena Teknologi Informasi (TI) memberikan peralatan yang dibutuhkan untuk operasional dan manajemen (Maksoud, S.S.A., \& Youssef, 2003).Salah satu bentuk perdagangan melalui Teknologi Informasi (TI) adalah e-commercehanya dengan klik pelanggan bisa mendapatkan barang yang diinginkan, bisa mengetahui apa saja yang diinginkan dan dapat melakukan transaksi dengan siapa saja tanpa dibatasi waktu dan jarak. Indikasi keunggulan e-commerce tersebut pada kenyataanya belum dimanfaatkan secara maksimal oleh kebanyakan UKM di Denpasar dengan berbagai sebab. Secara umum e-commerce merupakan fenomena yang akrab dalam kegiatan bisnis sekarang. Sudah banyak perpindahan barang dan pelayanan jasa yang dilakukan dengan lebih mudah, banyak dan tentunya cepat melalui jaringan dunia maya ini. Kegiatan dalam e-commerce sebenarnya tidak mengharuskan para pemasok, agen dan produsen untuk membuat dan membangun website. Namun banyak cara yang dapat dilakukan untuk mencari dan menawarkan barang dan jasa selain dengan website antara lain dengan menggunakan situs pertemanan, blog dan situs lainnya.

Rainer, R.K.,\& Cegielski, (2011) mengemukakan bahwa electronic commerce (ecommerce )menggambarkan proses membeli, menjual, mentransfer, atau bertukar produk, jasa, atau informasi melalui jaringan komputer, termasuk internet. Di Indonesia, fenomena ecommerce dikenal sejak tahun 1996 dengan munculnya situs http://www.sanur.com sebagai took buku online pertama. Dari sisi pemanfaatan peluang, setidaknya sampai saat ini ecommerce merupakan solusi efektif bagi para pengusaha khususnya pengusaha kecil dan menengah untuk menembus pasar global yang pada akhirnya akan meningkatkan daya saing ekonomi nasional. E-commerce juga memungkinkan perusahaan untuk memperluas jangkauan bisnis mereka. Salah satu manfaat utama dari e-commerce adalah akses ke dan dari pasar global. E-commerce menghilangkan hambatan geografis beberapa perusahaan yang ingin melakukan perdagangan global. Munculnya kegiatane-commerce ini harus dapat diantisipasi dengan tepat dan baik agar tidak kehilangan peluang meraih kesempatan dalam era globalisasi, terutama di bidang ekonomi. Pengusaha

\section{METODOLOGI PENELITIAN}

Metode atau metodologi adalah proses, prinsip, prosedur yang kita gunakan untuk mendekati problem dan mencari jawaban. Dengan ungkapan lain, metodologi adalah suatu pendekatan umum untuk mengkaji topik penelitian(deddy mulyana, 2004). Jenis penelitian yang digunakan adalah pendekatan kualitatif, yaitu penelitian yang digunakan untuk meneliti pada kondisi obyek alamiah, peneliti adalah sebagai instrumen kunci, teknik pengumpulan data dilakukan secara kualitatif, analisis data bersifat induktif/kualitatif, dan hasil penelitian kualitatif lebih menekankan makna daripada generalisasi (Sugiyono, 2014). Jenis penelitian 


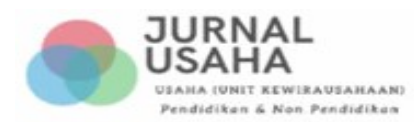

Vol 1, No. 1 (2020), June 2020

E-ISSN: 2746-2471

termasuk dalam penelitian eksploratif yaitu dilakukan untuk mengetahui dan menjelaskan permasalahan yang awalnya peneliti hanya memahami permasalahan yang ada secara umum, baru kemudian peneliti melakukan penelitian. Penelitian pada hakikatnya merupakan salah satu rangkaian kegiatan ilmiah baik untuk keperluan mengumpulkan data, menarik kesimpulan atas gejala-gejala tertentu dalam gejala empirik(Bungin B., 2011). Metode penelitian menggunakan studi literatur yaitu peneliti menelaah secara tekun akan kepustakaan yang diperlukan dalam penelitian (Nazir, 2014) dan juga mengkombinasikan dengan menggunakan wawancara pada informan yang diperlukan dalam penelitian. Metode penelitian yang digunakan adalah studi literatur secara sistematis(Espitia et al, 2016). Adapun teknik pengumpulan data dilakukan dengan menggunakan data sekunder dengan membandingkan dari wawancara dan data pendukung lainnya, dimana informan adalah pucuk pimpinan dari platform e-commerce digital business.

Dalam penelitian kualitatif pendekatan studi literatur ini, peneliti menggunakan tools NVivo 10, dimana tools ini telah diakui secara internasional untuk melakukan penelitian kualitatif. Dalama NVivo, sumber data penelitian (internals), sumber data penelitian eksternal (Externals), catatan-catatan peneliti selama pengumpulan data (memos), dan kerangka matriks (framework matrices). Internal Sources dalam konteks ini merupakan semua sumber data penelitian kualitatif yang dapat dimasukan kedalam NVivo, misalnya, rekaman-rekaman wawancara, transkrip wawancara, catatan-catatan selama melakukan penelitian, foto-foto, table data survey, isi website tertentu, data bases dan bahkan video-video(Bandur, 2016).

\section{HASIL DAN PEMBAHASAN}

Platform e-commerce pemain digital bisnis dalam mendukung kesuksesan UMKM di Indonesia adalah amat penting dalam mendukung kegiatan aktivitas usaha yang mereka lakukan. Hasil penelitian dalam kajian ini disajikan secara lengkap pada Matrik wawancara dari masing masing pimpinan, terlampir dibawah ini yang mengambarkan mengenai dukungan terhadap umkm dan model bisnis platform e-commerce pemain digital business sebagai berikut (Elsi anismar et al, 2019):

\begin{tabular}{|c|c|c|c|}
\hline No & $\begin{array}{c}\text { PEMAIN } \\
\text { DIGITAL } \\
\text { BISNIS }\end{array}$ & DUKUNGAN UMKM & MODEL BISNIS \\
\hline 1 & BUKALAPAK & $\begin{array}{l}\text { - Sejak akhir } 2017 \text { meluncurkan mitra } \\
\text { Bukalapak, yang menjadikan pemilik } \\
\text { warung sebagai mitra dalam menjual } \\
\text { produk digital (pulsa, paket data, } \\
\text { token listrik, tagiahan PDAM, BPJS, } \\
\text { dll). Hingga saat ini Bukalapak telah } \\
\text { menggandeng } 500 \text { ribu mitra warung } \\
\text { dan } 700 \text { ribu agen individu/ pelakuk } \\
\text { usaha mandiri. } \\
\text { Memiliki komunitas pelapak yang } \\
\text { tersebar di } 150 \text { kota dengan anggota }\end{array}$ & $\begin{array}{l}\text { - Bukalapak } \\
\text { mempunyai fitur- } \\
\text { fitur yang bisa } \\
\text { dibeli oleh pelapak } \\
\text { secara opsional } \\
\text { untuk } \\
\text { meningkatkan } \\
\text { performa bisnisnya, } \\
\text { misalnya iklan, dan } \\
\text { dashboard. } \\
\text { Profit sharing }\end{array}$ \\
\hline
\end{tabular}




\begin{tabular}{|c|c|c|c|}
\hline & & $\begin{array}{l}\text { sekitar } 5.000 \text { orang. } \\
\text { Memiliki tim khusus (community } \\
\text { management) untuk mendampingi } \\
\text { pelapak, sehingga jika ada input atau } \\
\text { masalah akan dengan mudah } \\
\text { tersampaikan. } \\
\text { Pada } 2019 \text { Bukalapak } \\
\text { mengalokasikan Rp 1 triliun untuk } \\
\text { mengembangkan platform mitra } \\
\text { Bukalapak. }\end{array}$ & $\begin{array}{l}\text { dengan mitra } \\
\text { Bukalapak, apabila } \\
\text { pelanggan membeli } \\
\text { produk digital di } \\
\text { mitra Bukalapak } \\
\text { maka } \\
\text { keuntungannya } \\
\text { akan dibagi dengan } \\
\text { Bukalapak. } \\
\text { Terdapat fitur } \\
\text { "Pembelian } \\
\text { Prioritas" } \\
\text { pelanggan bagi } \\
\text { Bukalapak yang } \\
\text { dapat dibeli untuk } \\
\text { mendapatkan } \\
\text { beberapa } \\
\text { keuntungan (gratis } \\
\text { ongkos } \\
\text { berkali }- \text { kirim } \\
\text { cashback, hali, } \\
\text { khusus untuk TV } \\
\text { berlangganan, dll) }\end{array}$ \\
\hline & TOKOPEDIA & 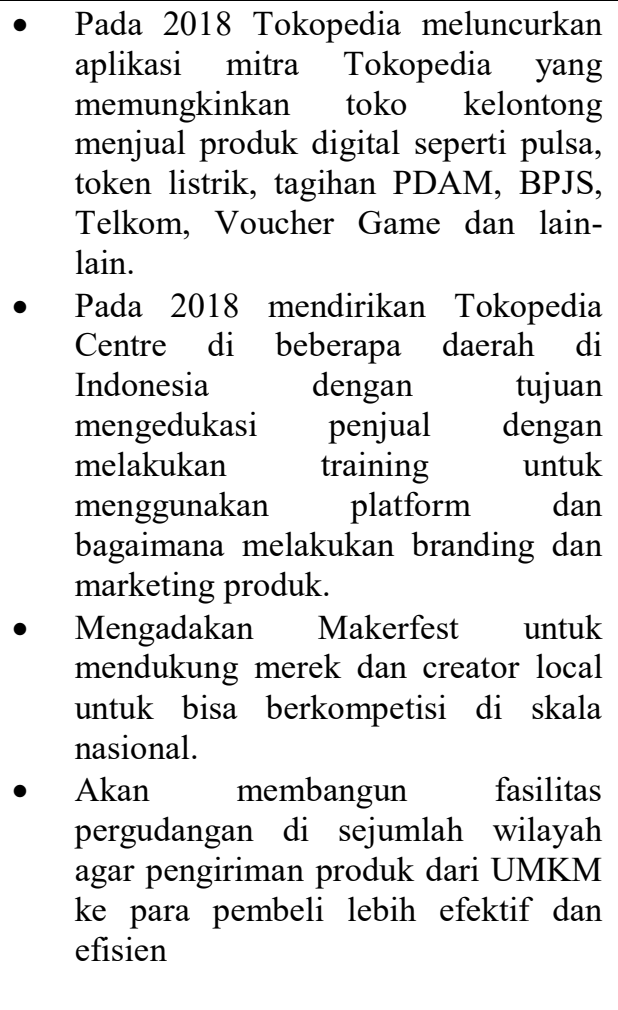 & 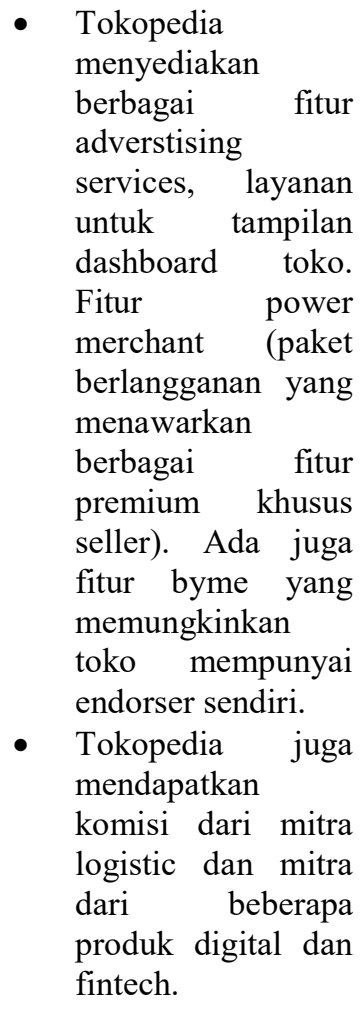 \\
\hline 3 & KUDO & $\begin{array}{l}\text { - Mempunyai visi memberdayakan } \\
\text { pengusaha kecil dan menengah untuk }\end{array}$ & $\begin{array}{ll}\text { - } & \begin{array}{l}\text { Pendapatan } \\
\text { bersumber }\end{array} \\
\text { dari }\end{array}$ \\
\hline
\end{tabular}




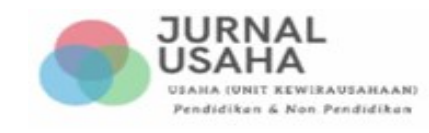

Vol 1, No. 1 (2020), June 2020

E-ISSN: 2746-2471

maju dan lebih produktif.

- Berhasil menambah pendapatan agen kudo (warung/ toko kecil) antara 10\%-30\%.

- Mempunyai Tim lapangan yang cakupan daerahnya sangat luas, sampai kedaerah pelosok. margin yang

diberikan supplier

dan fee dari

layanan reveral produk, serta akan mengembangkan sumber pendapatan potensial dari layanan financial serta pembiayaan mikro.

\begin{tabular}{|c|c|c|c|}
\hline 4 & GRAB & $\begin{array}{l}\text { - } \text { Sekitar } 80 \% \text { dari merchant Grab } \\
\text { Food merupakan UMKM. Grab Food } \\
\text { sudah hadir di } 178 \text { kota dan } \\
\text { kabupaten di Indonesia. } \\
\text { - Grab bekerja sama dengan Tokopedia } \\
\text { dimana merchant Tokopedia dapat } \\
\text { menggunakan layanan Grab Express } \\
\text { untuk pengiriman barang. } \\
\text { Memberdayakan 5 juta wirausahawan } \\
\text { mikro di Indonesia pada tahun } 2018 \\
\text { untuk meningkatkan pendapatan } \\
\text { mereka. } \\
\text { Mengadakan seminar tentang } \\
\text { pemasaran digital untuk para } \\
\text { wirausahawan di berbagai daerah. }\end{array}$ & $\begin{array}{l}\text { - Grab menerapkan } \\
\text { sistem bagi hasil } \\
\text { dengan mitranya } \\
\text { baik driver ataupun } \\
\text { merchant. Selain } \\
\text { itu driver juga } \\
\text { mendapatkan } \\
\text { bonus. }\end{array}$ \\
\hline & GOJEK & 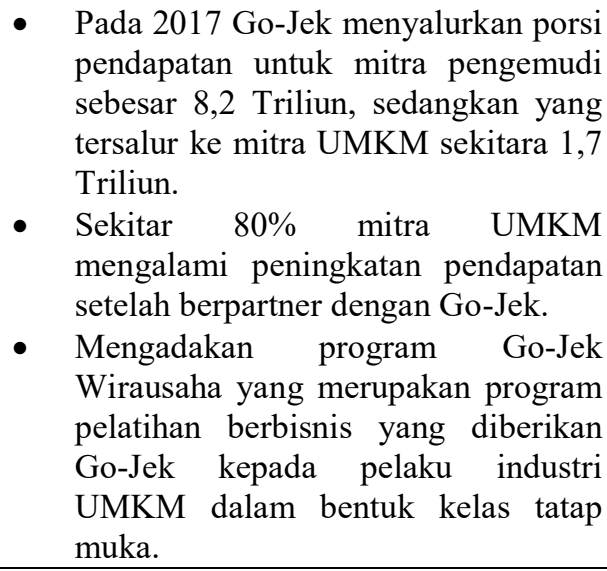 & $\begin{array}{l}\text { - Menerapkan sistem } \\
\text { bagi hasil kepada } \\
\text { mitra pengemudi, } \\
\text { merchant Go-Food, } \\
\text { Go-Massage, Go- } \\
\text { Clean dan Go- } \\
\text { Glam. Disamping } \\
\text { itu mitra deliver } \\
\text { juga mendapatkan } \\
\text { bonus. }\end{array}$ \\
\hline
\end{tabular}

Dari matrik diatas menghasilkan beberapa pembahasan antara lain:

Word Frequency Queries

Yaitu mengeksplorasi kata-kata yang paling sering muncul dalam data penelitian. Dengan alat analisis ini, kata-kata yang memilik makna yang sama dapat dikategorikan dalam kelompok yang sama. 
Vol 1, No. 1 (2020), June 2020

E-ISSN: 2746-2471

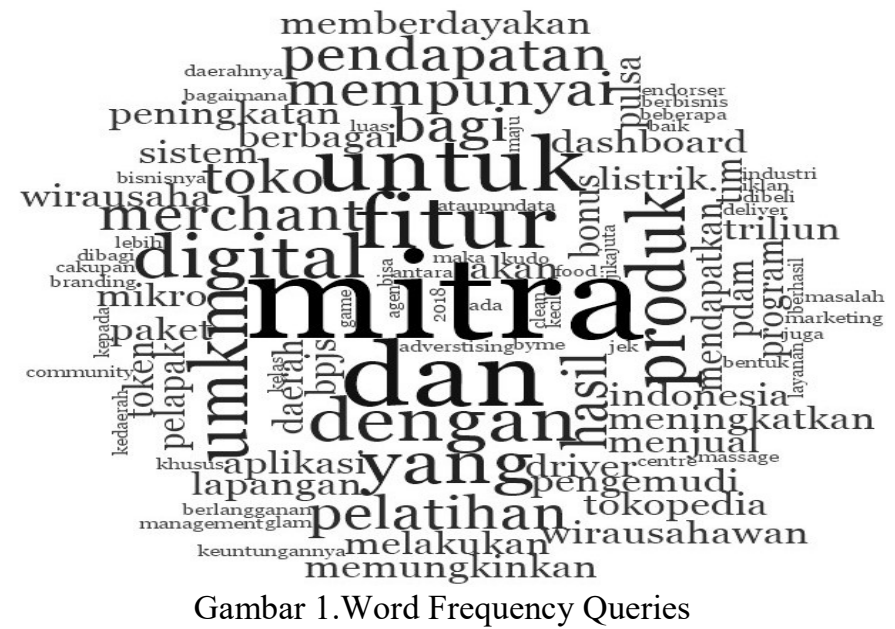

Dari analisis diatas untuk kata yang paling dominan adalah Mitra, Fitur, Produk, UMKM, Digital, merchant dan toko dapat diartikan bahwa seluruh pemain digital business fokus mengenai platform e-commerce terutama pada bagian kata-kata bertulis tebal tersebut.

Analisis Klaster

Membandingkan kata-kata yang terdapat dalam sumber data atau ingin membandingkan kesamaan kata-kata dalam tema-tema hasil koding yang tersimpan dalam nodes. Dalam Analisis Klaster ini dapat diukur mengenai korelasi (Pearson Coffecient).

Tabel 1. Analisis Klaster

\begin{tabular}{|c|c|c|}
\hline Code A & Code B & $\begin{array}{l}\text { Pearson } \\
\text { correlation } \\
\text { coefficient }\end{array}$ \\
\hline Nodes $\backslash \backslash$ Bagi Hasil MB & Nodes $\backslash \backslash$ MODEL BISNIS $\backslash$ Bagi hasil & 1 \\
\hline Nodes $\backslash \backslash$ Fitur MB & Nodes $\backslash \backslash$ MODEL BISNIS $\backslash$ Fitur & 1 \\
\hline $\begin{array}{l}\text { Nodes } \backslash \backslash \text { DUKUNGAN } \\
\text { UMKM } \backslash \text { Memberdayakan } \\
\text { wirausahawan mikro }\end{array}$ & $\begin{array}{l}\text { Nodes } \backslash \backslash \text { memberdayakan } \\
\text { wirausahawan mikro }\end{array}$ & 1 \\
\hline $\begin{array}{c}\text { Nodes } \backslash \backslash \text { Memiliki komunitas pelapak } \\
\text { yang tersebar di } 150 \text { kota anggota } \\
\text { sekitar } 5.000 \text { orang. }\end{array}$ & $\begin{array}{c}\text { Nodes } \backslash \text { DUKUNGAN } \\
\text { UMKM } \backslash \text { memiliki komunitas pelapak } \\
\text { yang }\end{array}$ & 1 \\
\hline Nodes $\backslash \backslash$ mendapatkan bonus MB & Nodes $\backslash \backslash$ MODEL BISNIS $\backslash$ Bonus & 1 \\
\hline $\begin{array}{l}\text { Nodes } \backslash \backslash \text { DUKUNGAN UMKM } \backslash \text { Menjual } \\
\text { produk digital }\end{array}$ & Nodes $\backslash$ MODEL BISNIS $\backslash$ Fitur & 1 \\
\hline $\begin{array}{l}\text { Nodes } \backslash \backslash \text { DUKUNGAN UMKM } \backslash \text { Menjual } \\
\text { produk digital }\end{array}$ & Nodes $\backslash \mid$ Fitur MB & 1 \\
\hline Nodes $\backslash \backslash$ menjual produk digital & Nodes $\backslash$ MODEL BISNIS $\backslash$ Fitur & 1 \\
\hline
\end{tabular}


Vol 1, No. 1 (2020), June 2020

E-ISSN: 2746-2471

Nodes $\backslash \backslash$ menjual produk digital

Nodes $\backslash \backslash$ menjual produk digital

Nodes $\backslash$ pelatihan
Nodes $\backslash \backslash$ Fitur MB 1

Nodes $\backslash$ DUKUNGAN 1

UMKM $\backslash$ Menjual produk digital

Nodes $\backslash$ DUKUNGAN

UMKM $\backslash$ Pelatihan

Gambar 2. Analisis Klaster

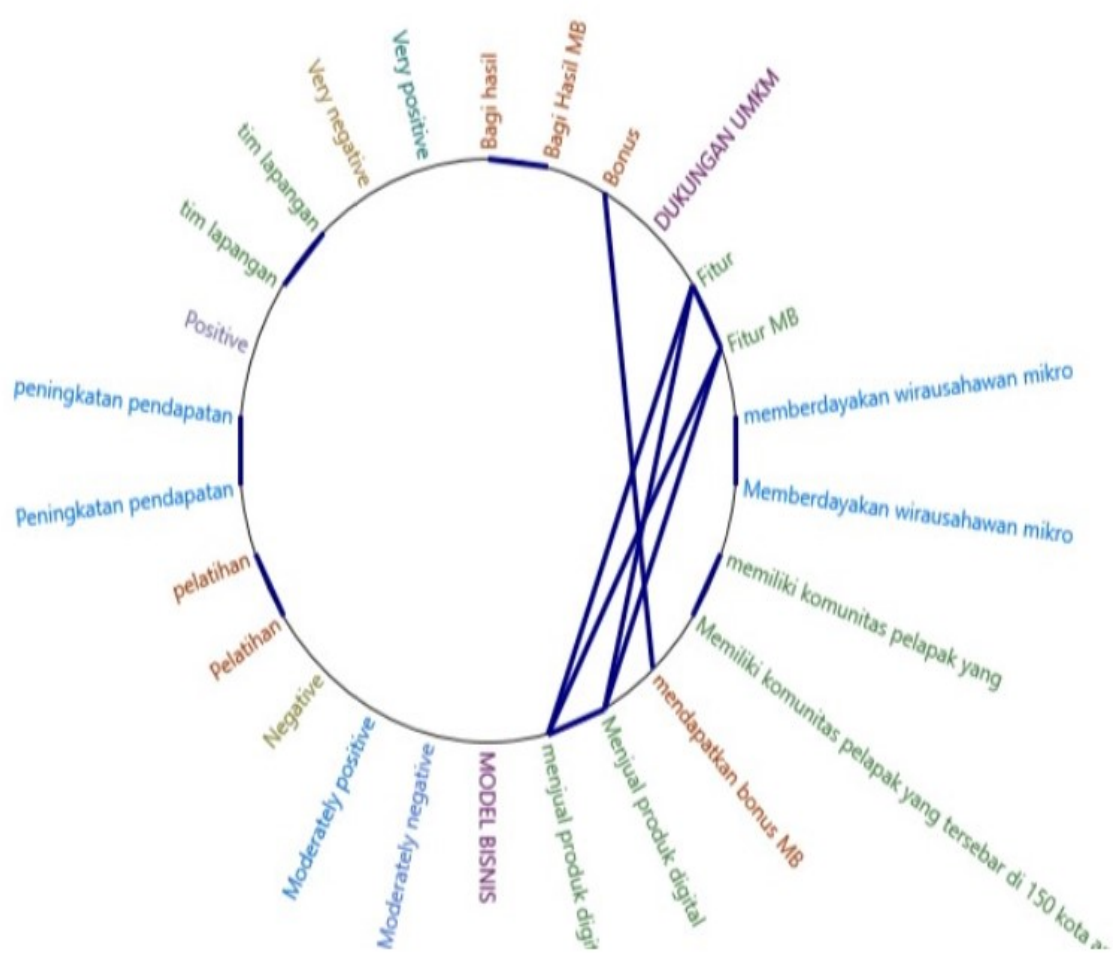

Hasil analisis diatas baik dari Tabel 1 maupun Gambar 2 hanya beberapa tema yang memiliki korelasi kuat (Pearson Coefficient) yaitu mempunyai nilai 1 yaitu: Menjual Produk Digital, Bonus, Fitur dalam aplikasi, artinya semua pemain digital business terhadap umkm lebih condong kepada Menjual Produk Digital, Bonus yang diharapkan mitra dan Fitur dalam aplikasi yang mudah dan dapat membantu dalam proses penjualan.

\section{Project Map}

Salah satu fitur yang terdapat di NVivo untuk menampilkan hasil dari penelitian adalah berbentuk Map. Istilah yang digunakan sebelumnya pada NVivo adalah Model, namun kini sudah diganti dengan istilah Map. Project Map: Map yang bersumber dari coding yang telah dibuat sebelumnya, baik itu Files, Nodes, maupun Relationships, hal ini mengacu pada tema-tema hasil koding sehingga dapat mevisualisasikan hasil koding. 
Vol 1, No. 1 (2020), June 2020

E-ISSN: 2746-2471

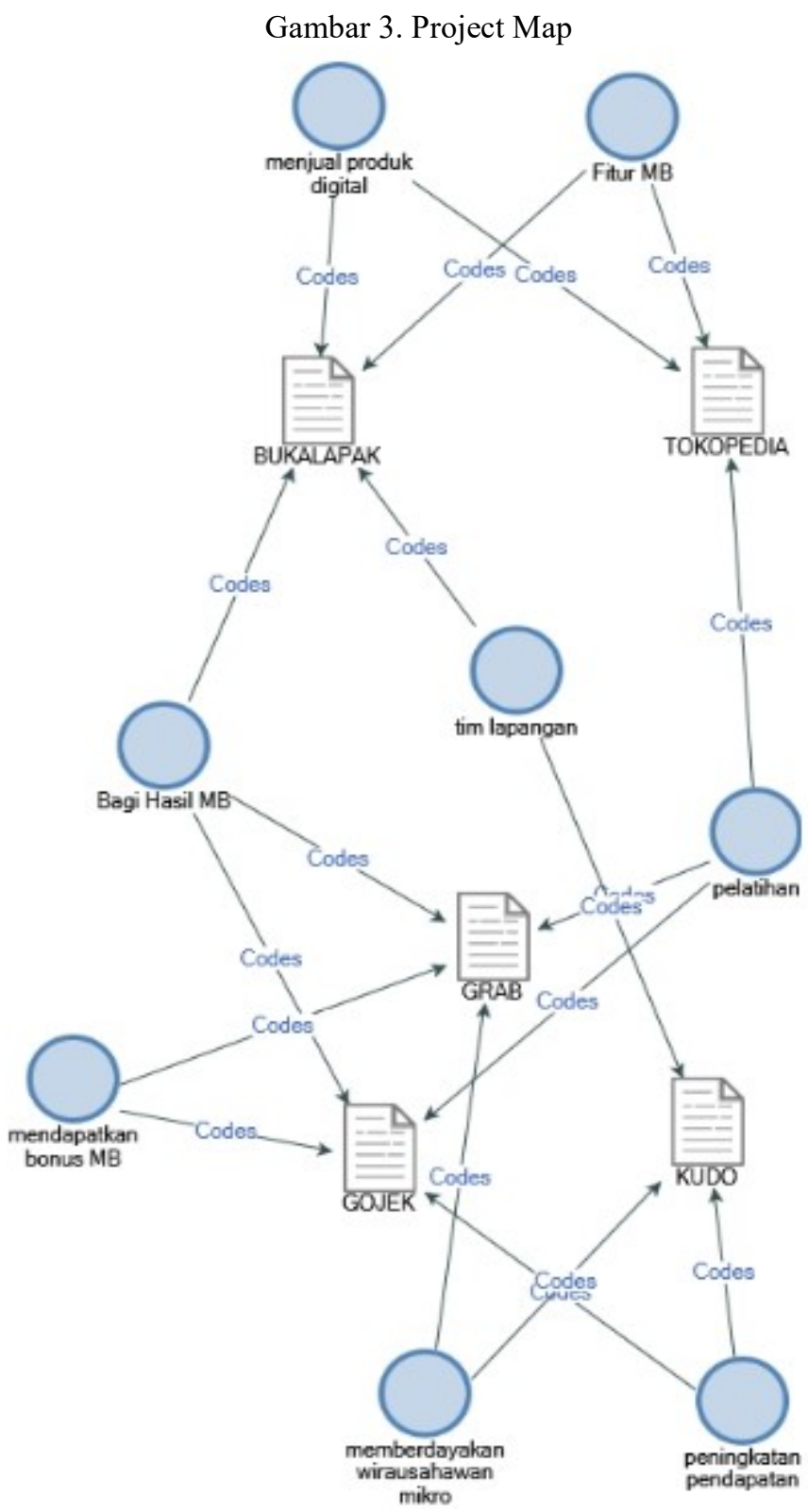

Dari Map atau model diatas bahwa masing-masing pemain digital mempunyai fokus kepada mitra dari BUKALAPAK (B), TOKOPEDIA (T), GRAB (GR), GOJEK (GO) \& KUDO (K) dengan beberapa variasi antara lain, B \& T: Menjual produk digital dan Fitur, B, GR \& GO: Bagi Hasil atau Profit Sharing, B \& K: Tim lapangan, T \& GR: Pelatihan, GO \& GR: Bonus, GO \& K: Peningkatan pendapatan, dan GR \& K: Memberdayakan wirausahawan mikro. 
Vol 1, No. 1 (2020), June 2020

E-ISSN: 2746-2471

\section{Diagram perbandingan}

Diagram perbandingan pada dasarnya untuk membantu dalam membandingkan tematema secara khusus untuk menjelaskan perbandingan secara mendetail. Diagram ini juga membandingkan partisipan yang satu dengan yang lain atau data setting penelitian.

Gambar 4.Diagram perbandingan

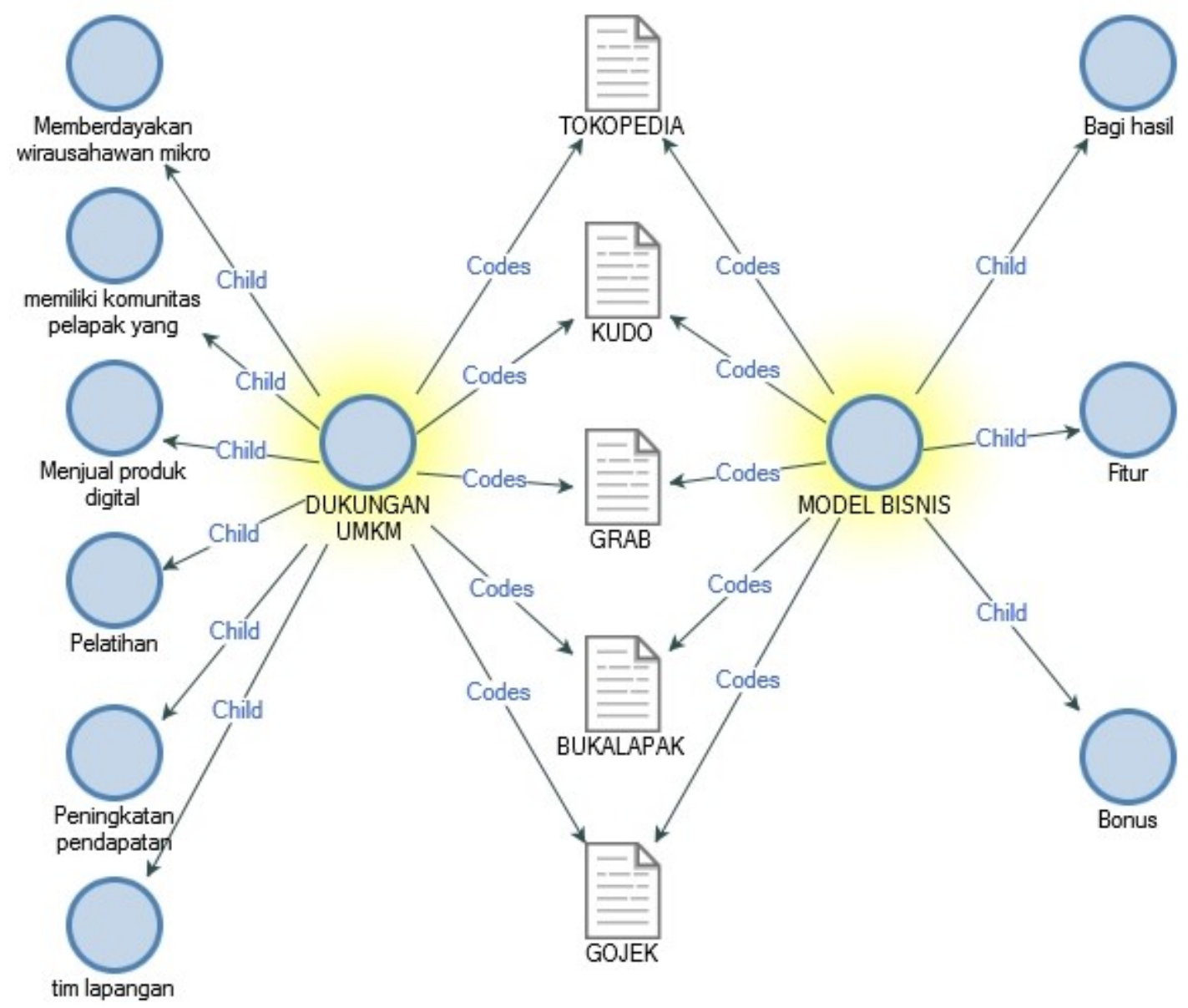

Dari gambar diatas bahwa pemain digital bisnis terutuma pada dukungan UMKM adalah lebih fokus pada: memberdayakan wirausahawan mikro, memiliki komunitas, menjual produk digital, pelatihan, peningkatan pendapatan dan tim lapangan yang membantu. Sedangkan untuk model bisnis fokus pada pembagian hasil atau profit sharing, Fitur dalam aplikasi dan Bonus bagi mitra. 
Vol 1, No. 1 (2020), June 2020

E-ISSN: 2746-2471

\section{E. SIMPULAN DAN SARAN}

Adapun untuk perbandingan dari 5 pemain digital bisnis dimana dipecah menjadi 2 (dua) yaitu mendukung UMKM terdiri Memberdayakan wirausahwan mikro, memiliki komunitas, menjual produk digital pelatihan, peningkatan pendapatan dan tim lapangan, dan model bisnis yaitu bagi hasil atau profit sharing, apliksi fitur serta bonus bagi mitra.

Untuk model menghasilkan model terbaru terbentuk dari 5 pemain digital bisnis baik itu mendukung UMKM dan model bisnis yaitu saling mendukung satu sama lainnya, dimana BUKALAPAK dan GOJEK yang mempunyai paling dominan sebanyak 4 tema. BUKALAPAK yaitu menjual produk digital, aplikasi fitur, bagi hasil dan tim lapangan, dari 4 tema tersebut 3 dari tema mendukung UMKM dan hanya 1 tema dari model bisnis. Sedangkan GOJEK yaitu Bagi hasil atau profit sharing, mendapatkan bonus bagi mitra, pelatihan dan peningkatan pendapatan. Dari 4 tema yang muncul, 2 berasal dari mendukung UMKM dan 2 dari model bisnis. Sebaliknya yang paling sedikit adalah TOKOPEDIA dan KUDO yang masing-masing hanya 2 tema yaitu pelatihan, aplikasi fitur, peningkatan pendapatan dan tim lapangan yang membantu, hanya 1 dari model bisnis yaitu aplikasi Fitur.

Hasil dari permodelan diatas telah membentuk tema yang paling mayoritas untuk mendukung kesuksesan UMKM di Indonesia baik itu dari mendukung UMKM ataupun model bisnis.

Hasil dari penelitian ini diharapkan dapat berguna bagi pemain digital bisnis yang fokus menggarap UMKM di Indonesia lebih maju, dan diharapkan dari penelitian ini dikembangkan lebih besar lagi baik itu informan maupun data pendukung dalam membantu proses penelitian hingga kelak dapat menjadi kebijakan ecommerce UMKM di Indonesia. 


\section{DAFTAR PUSTAKA}

Bandur, A. (2016). Penelitian kualitatif Metodologi, Desain dan Teknik Analisis Data dengan Nvivo 11 plus. jakarta: Mitra Wacana Media.

Bungin B. (2011). Metodologi Penelitian Kualitatif. jakarta: rajawali pers.

Deddy mulyana. (2004). Metodologi Penelitian Kualitatif (Paradigma Baru Ilmu Komunikasi Dan Imu Sosial lainnya). Bandung: PT Remaja Rosmadakarya,.

Elsi anismar et al. (2019). Platform Pemberdaya UMKM. SWA, 22-47.

Espitia et al. (2016). Systematic Literature Review of the Implementation of Knowledge Codification Process. In European Conference Knowledge Management (p. 1111). Passau: Academic Conferences International Limited.

Maksoud, S.S.A., \& Youssef, M. A. . (2003). Information and Communication Technology for Small and Medium Enterprises in Egypt (Case Study).Cairo: SME Development Unit Ministry if Foreign Trade Egypt.

Nazir. (2014). Metode Penelitian. jakarta: Ghalia Indonesia.

Pramdia Arhando Julianto. (2020). Tahun 2020 Ditargetkan 80 Persen Produk UMKM Kuasai Pasar E-commerce. Retrieved from https://ekonomi.kompas.com/read/2017/10/02/220000826/tahun-2020-ditargetkan-80persen-produk-umkm-kuasai-pasar-e-commerce.

Rainer, R.K.,\& Cegielski, C. . (2011). Introduction to Information Systems: Supporting and Transforming Business (3rded.). usa: John Wiley \& Sons.

Sugiyono. (2014). Metode Penelitian Kuantitatif, Kualitatif, dan Kombinasi (Mixed Methods). Bandung: alfabeta.

Sutaryo. (2004). Pengaruh Karakteristik Inovasit terhadap Adopsi Teknologi Internet oleh UMKM. Journal Ekonomi Dan Keuangan, II(2), 290.

Widianto, S. (2019). Butuh Trik Jika UMKM Berdagang di Marketplace. Retrieved from https://www.pikiran-rakyat.com/ekonomi/pr-01319017/butuh-trik-jika-umkmberdagang-di-marketplace 